\title{
Plutarch
}

\section{Dialog über die Liebe}

Amatorius

Eingel., übers. u. mit interpretierenden Essays versehen v. Herwig Görgemanns, Barbara Feichtinger, Fritz Graf, Werner G. Jeanrond u. Jan Opsomer

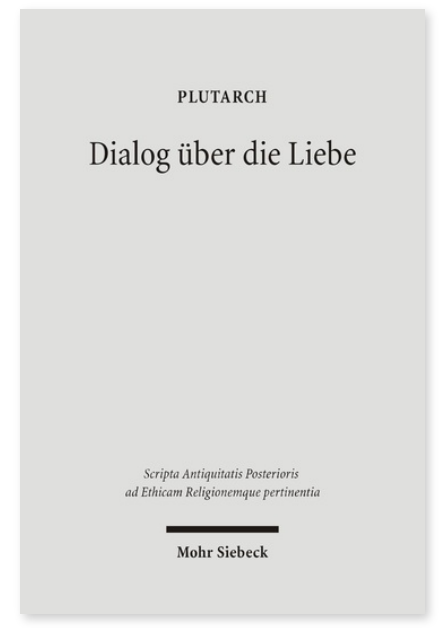

2006. X, 323 Seiten. SAPERE X

ISBN 978-3-16-156445-1

DOI 10.1628/978-3-16-156445-1

eBook PDF
Plutarch gibt der Liebesphilosophie Platons eine neue Wendung: er überträgt deren Grundgedanken auf die eheliche Liebe, und er verteidigt die Bedeutung der Sexualität für Persönlichkeitsentwicklung und menschliche Bindung. Sein Dialog ist kunstvoll gebaut. Er findet während des Eros-Festes in Thespiai statt (religiöse Dimension); eine Hintergrundhandlung hat Züge einer Komödie (Entführung eines Jünglings durch eine reife Witwe); der Autor läßt sich selbst als frischverheirateten, verliebten jungen Mann auftreten (doppelte Autorenperspektive). Die Schrift wird hier vorgelegt mit einer literarisch orientierten Einführung, kritisch durchgesehenem griechischen Text, einer möglichst lesbaren deutschen Übersetzung und eingehenden Einzelerklärungen. Vier Essays verschiedener Autoren kommen hinzu: über den Eros-Kult in Thespiai, über die philosophischen Aspekte der Schrift, über sozialgeschichtliche Voraussetzungen der Gedanken über Sexualität und Ehe, über den christlichen Liebesbegriff.

\section{Inhaltsübersicht}

Plutarch gibt der Liebesphilosophie Platons eine neue Wendung: er überträgt deren Grundgedanken auf die eheliche Liebe, und er verteidigt die Bedeutung der Sexualität für Persönlichkeitsentwicklung und menschliche Bindung. Sein Dialog ist kunstvoll gebaut. Er findet während des Eros-Festes in Thespiai statt; eine Hintergrundhandlung hat Züge einer Komödie und der Autor läßt sich selbst als frischverheirateten, verliebten jungen Mann auftreten. Die Schrift wird hier vorgelegt mit einer literarisch orientierten Einführung, kritisch durchgesehenem griechischen Text, einer möglichst lesbaren deutschen Übersetzung und eingehenden Einzelerklärungen. Vier Essays verschiedener Autoren kommen hinzu: über den Eros-Kult in Thespiai, über die philosophischen Aspekte der Schrift, über sozialgeschichtliche Voraussetzungen der Gedanken über Sexualität und Ehe, über den christlichen Liebesbegriff.

Plutarch Keine aktuellen Daten verfügbar.

Barbara Feichtinger Geboren 1963; ist Professorin für Latinistik an der Universität Konstanz.

Fritz Graf Geboren 1944; ist Professor of Greek and Latin an der Ohio State University und Leiter des Center for Epigraphical Studies ebendort.

Werner G. Jeanrond Geboren 1955; ist Professor für Systematische Theologie an der Universität Lund in Schweden.

Jan Opsomer Geboren 1966; ist Professor für Philosophie an der Katholischen Universität Leuven.

Jetzt bestellen:

https://mohrsiebeck.com/buch/dialog-ueber-die-liebe-9783161564451?no_cache=1

order@mohrsiebeck.com

Telefon: $+49(0) 7071-923-17$

Telefax: $+49(0) 7071-51104$ 